\title{
What Is Interesting About Equivalence Relations and Behavior?
}

\author{
Murray Sidman ${ }^{1}$
}

Published online: 18 April 2018

(C) Association for Behavior Analysis International 2018

Keywords Meaning $\cdot$ Stimulus equivalence $\cdot$ Stimulus relations $\cdot$ Creativity Induction

Why should you, a potential reader, be interested in equivalence relations? Because you will come from many different backgrounds and will have many different interests, I cannot answer that question directly. The best I can do to indicate why you might find equivalence relations worth reading about is to tell why I find equivalence relations worth experimenting and writing about.

\section{Words and Other Symbols Versus Things and Events}

A major source of my own interest has been what seems to me a central role of equivalence relations in making language such a powerful factor in our everyday social intercourse with each other. I think we can agree that words have meanings, even while we recognize that the term meaning may itself have many meanings. One kind of word meaning is symbolic reference: many words are symbols; they refer to other things or events. As Skinner pointed out in arguing against what he called reference theories of meaning (Skinner, 1957, pp. 7-10, 86-89, 114-129), statements about meanings, symbols, and referents do not explain verbal behavior. Such statements are verbal

Editor's note: By providing a clear and accessible and glimpse into the line of inquiry that led to Murray Sidman's first studies of stimulus equivalence, this essay explains much about why the topic is compelling, both conceptually and experimentally. The essay is reproduced, with author permission, from Sidman (1994), Equivalence relations and behavior: A research story (pp. 2-17). Boston: Authors Cooperative. It has been very lightly edited for flow and formatting.

Murray Sidman

murraysidman@comcast.net

1 Association for Behavior Analysis International, Sarasota, FL, USA 
behavior, and as such, they themselves require explanation. Nevertheless, they summarize real observations. We can-and do-specify the referent of a word or other symbol by giving the referent other names, by pointing to it or acting in other ways with respect to it, by specifying its opposite in a name or another action, by speaking or otherwise acting differently in its absence, and so on. But to me, one of the most fascinating observations is that we often react to words and other symbols as if they are the things or events they refer to. Even though we do not treat word and referent as equal in all respects, we attribute some of the same properties to both. This treatment of linguistic forms as equivalent to their referents permits us to listen and read with comprehension, to work out problems in their absence, to instruct others by means of speech or text, to plan ahead, to store information for use in the future, and to think abstractly - all of these by means of words that are spoken, written, or thought in the absence of the things and events they refer to.

On the other hand, the substitution of words and other symbols for their referents may also bring about some extraordinary, even bizarre, conduct. Let me just touch on some examples of that type, ranging from magical thinking to the highest realms of human creativity. I bring these up not because they are usual but because they illustrate the power of symbolic reference.

During recent years, two instances in which people reacted to nonlanguage symbols as if they were the things they represented were so spectacular that the news media featured them prominently for a long time One of these was the flag-burning controversy in the United States. In response to the destruction of a few American flags, mobs gathered to defend the country against attack and to mount counterattacks. Members of our governing bodies interrupted the processing of much needed legislation and other governmental functions so that they could make themselves popular and gain votes by declaiming in outrage against the fiery destruction of our institutions. The burning of flags was not just a threat; it was actual war. Those who burned the flags knew this would be the reaction; that is why they chose flag-burning as their way of protesting. Although flag burning is in itself a nonviolent act-it touches no person; it destroys nobody's property - they knew it would receive the kind of public notice that is ordinarily provoked by actual violence against people or property and against our system of government.

A second media-celebrated event occurred during the hectic days when the communist government of Russia was falling. I watched TV in fascination as a crowd of enraged Russian citizens hurled both invective and stones at a famous statue of Lenin and then wrestled it to the ground, jumped on it, kicked it, and pounded it with hammers. The statue, of course, was not alive - was not Lenin himself-but people were still trying to kill it.

Happenings analogous to these are not confined to nonlinguistic representations. The treatment of language symbols as if they are the things they represent is so strongly and deeply ingrained that we often react to words with feelings of pain, and we use words to inflict pain. A familiar adage, meant especially but not exclusively for children, is intended specifically to counteract this feature of words: "Sticks and stones may break my bones, but names can never hurt me." In fact, words are considered to be hurtful. Witness what has now become commonplace in our daily news: first, killings after the receipt of actual or imagined verbal insults and, second, such killings then being justified even in the courtroom as self-defense. 
An insightful picture of words being taken as their referents comes from the description of a character in a novel by David Grossman (1989):

[He] lives totally in a world of words, which means, I imagine, that every word he utters or hears has for him a sensual quality which I cannot perceive. Is it possible, then, that the word "supper" is enough to satisfy his hunger? That the word "sore" cuts his flesh? That the word "living" enlivens him? ... Could it be that [he] became a fugitive from human language in order to protect himself from all the words that cut his flesh? (p. 283).

Skinner (1957) pointed out that many distinctive characteristics of verbal behavior come from the fact that words have no power in themselves to change the environment: "Rarely do we shout down the walls of a Jericho or successfully command the sun to stop or the waves to be still. Names do not break bones" (p. 2). Any physical effects that our utterances accomplish must be mediated by the actions of listeners or readers. Stillwhat about the newspaper article (Mehegan, 1994) in which I read with amazement that:

A famous and controversial legal scholar clashes with a book critic, throwing a spotlight on a philosophical question: Is talking about committing a violent crime, even pretending to commit it, the same as actually doing it?

... In his fiercely negative review of MacKinnon's new book ... Romano begins with a complex hypothesis that he has raped MacKinnon in his imagination, then written about it as if he had done it. In an argument that mirrors her book's central thesis, an outraged MacKinnon charges that Romano's hypothesis in itself constitutes rape.

...[MacKinnon has argued for] a model law that would outlaw graphic words and images that tend to subjugate women. In her new book, MacKinnon advances the argument with ... such statements as, "To say it is to do it...."

Writers and book reviewers live in a world of words, so it is perhaps not surprising that many of them endow the source of their influence and livelihood with great importance and power. But it is certainly true that what we say can mirror our feelings, may be predictive of nonverbal actions we would take if we had the opportunity, or may incite or encourage others to take action, so words may realistically be reacted to with resentment and even fear. The prevention of such resentment and fear in everyday intercourse is one of the functions of society's rules of common courtesy, and a book review or any other verbal interaction may indeed go beyond those rules, as may a listener's or reader's verbal reactions. Nevertheless, we forget that no matter how outrageous or threatening they may be, no matter what they reveal about a speaker's or writer's attitudes or intentions, words can themselves produce no direct damage or hurt; for words to exert physical force requires nonverbal action by listeners or readers. Even though words may indicate intentions or desires, to say it is not to do it. What is perhaps to be legislated against is not the mere utterance or writing of words but the performance of hurtful actions that words often warn us of, or the verbal provocation of others to perform hurtful actions. 
I believe that equivalence relations underlie all these examples: the flag has become equivalent to our nation itself and its institutions; under some conditions, statues become equivalent to their models; a dent in the rear fender of one's car is equivalent to a slap in one's face; to complain about such a dent is equivalent to initiating a bodily assault; verbal hostility is taken as the equivalent of physical aggression; sharp words are the equivalent of sharp instruments; hypothesizing an action is equivalent to performing the action.

Examples of nonverbal symbols becoming equivalent to events and things in reality abound: advertising agencies have long recognized and promoted the equivalence of automobile size and penis size; changing a company's logo is expected to change the company itself, transforming it from an economic failure to a success; "clothes make the man," and the emperor unclothed is a mere mortal; pins are inserted into a doll in order to bring pain to a far-away person; property trespass is the equivalent of a threat to the property owner's life, thereby justifying the trespasser's destruction.

Examples of verbal symbols becoming equivalent to events and things in reality also abound: As we have learned from many of our political leaders, saying that poverty does not exist is equivalent to doing away with poverty as a problem, or saying that everybody has access to health care is equivalent to everybody actually receiving health care; in general, saying that poor is rich, war is peace, and offense is defense are equivalent to the elimination of poverty, war, and aggression, so nothing further need be done about these matters; for many theorists and model makers in science, the theories and models themselves, rather than the observations they are supposed to explain, become the primary subject matter (see, for example, Chiesa, 1994, pp. 52, 70, 158); in both science (Hineline, 1980) and religion (Schoenfeld, 1994, pp. 32-35, 96), verbs are often transformed into nouns or things, which are then dealt with as though they actually existed apart from their lexical status. Acts of remembering become a thing we call memory. Having been represented by a noun, memory can then be talked about as if it had qualitative and quantitative characteristics of its own, independently of the acts it refers to. Similarly, the origin of life, life after death, the birth of the universe, and so on are events that no living person has experienced; they must therefore be purely verbal constructions - words that are defined only by other words. But then, having invented those words, we go on to build scientific and religious systems around them. Words become equivalent not only to observed but also to hypothesized reality.

The treatment of words as equivalent to their referents is not necessarily disadvantageous or deceptive. Great accomplishments arise from our ability to manipulate words in the absence of their referents and even to manipulate words that have no referents except other words. Because of the equivalence of words to things and to other words, an Einstein can come up with a verbal construction like $E=m c^{2}$ that results not just in more words but in the creation of an atomic explosion or the sending of a rocket into outer space; we can translate architectural drawings into real buildings and bridges; we can categorize things and events by verbal labels so that we do not have to remember every experience uniquely; we can store data, specifications, descriptions, instructions, and many kinds of knowledge in books, disks, and tapes so that these can be passed on for use by future generations; we can communicate poorly understood but common and even universal experiences, feelings, and emotions by means of poetic and other forms of artistic expression.

In addition to instances of word-referent equivalence that can be culled from everyday experience, we have seen some striking examples in some of our laboratory 
studies of aphasic patients (Leicester, Sidman, Stoddard, \& Mohr, 1971). Although these observations were published in the same year as our first equivalence paper, they actually antedated that work by more than ten years, but even after we had started our direct experimental attack on equivalence phenomena, the significance of the earlier data took a while to sink in. Those data should have made us take a closer look.

Our subjects were people who had recently suffered stroke-induced brain damage and, in consequence, were having problems speaking, writing, and understanding spoken and written language. To help analyze their problems, we gave them simple matching-to-sample, naming, and writing tests. Here is a condensed account of the test methods (from Leicester et al., 1971):

The patients were tested in a quiet, softly lit room. They sat before a panel of nine translucent windows, each 2 -in square, arranged in a $3 \times 3$ matrix. Each trial began by presenting the sample stimulus. Visual samples (for example, printed words) were projected from the rear onto the center window of the matrix. Auditory samples were dictated from tapes over a speaker, and tactile samples were presented for palpation inside a screening box. In tests of matching to sample, the patient touched the center window to bring choice stimuli (for example, pictures) onto the outer windows of the matrix. One choice, the correct one, corresponded to the sample; the others did not. The patient selected and touched one of the choice windows. Correct selections caused a chimes to ring and a nickel ( 5 cents) to be delivered. After incorrect choices, there were no chimes or nickels. In some tests the sample remained after the choices appeared (simultaneous matching): in others, the sample disappeared when the subject touched the center key, and the choices appeared 0-40 sec later (delayed matching). The sample stimulus was presented in the same way for writing and oral naming tests. For writing tests, the patient had a new sheet of paper for each trial. Correct responses caused the ringing of the chimes and payment of a nickel.

The patient was given many trials with each type of task, the trials differing in the specific stimuli presented and in the arrangement of the stimuli on the windows. This was essential to avoid pitfalls of window-pressing preferences learning of trial sequences, imperfectly designed sets of trials, and so on. The methods are described in greater detail in Sidman, Stoddard, Mohr, and Leicester (1971).

In one type of test, the subjects matched printed numerals and quantities of dots. When the sample was a numeral, the choices were various quantities of dots, and vice versa, as illustrated in Fig. 1. Other tests offered the subjects the dots as choices but the samples were auditory (dictated) instead of visual. What we were asking the patients to do was to relate certain symbols (visual numerals and auditory number names) to some of their referents (quantities). The matching tests were of particular interest because they permitted us to examine how aphasic patients related symbols and referents to each other without having to speak.

Our test methods allowed us to observe not only that subjects made mistakes with these simple materials, which they would have matched perfectly before their illness, but that their errors were not random. For example, Fig. 2 shows one subject's generalization gradient in which the choice on any trial is specified by its numerical 

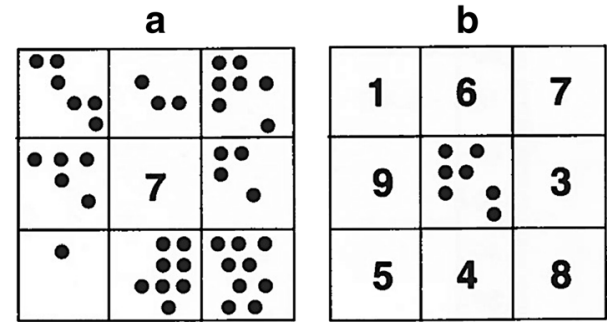

Fig. 1 Tests with numerals and dots. Illustrative trials, simultaneous matching. a Visual numeral sample, dot choices. b Visual dot sample, numeral choices. Different patterns of dots were used on other trials

deviation from the sample. For example, when the sample was the written numeral, 7 , or the written or dictated number name, "seven," a subject's choice of 8 dots had a deviation of +1 ; nine dots, a deviation of $+2 ; 6$ dots, $-1 ; 1$ dot, -6 ; and so on; correct choices had a deviation of zero. This subject's actual errors are listed below the gradient. The main finding here was that the subject's incorrect choices were related to the samples by proximity in the number sequence. Other subjects also showed a preponderance of errors with small deviations from the sample.

These tests required subjects to match stimuli that were only arbitrarily relatednumerals, printed or dictated number names, and quantities of dots bore no physical resemblance to each other. Lissauer (1890), in his studies of what he called "mindblindness," characterized such symbolic reference as an "inner relation" that depended on language. One might, instead, take a more parsimonious view of our test results: perhaps the subject's errors were due not to any problem with symbolic reference but simply to imprecise counting of the dots. A second kind of test, however, suggested a

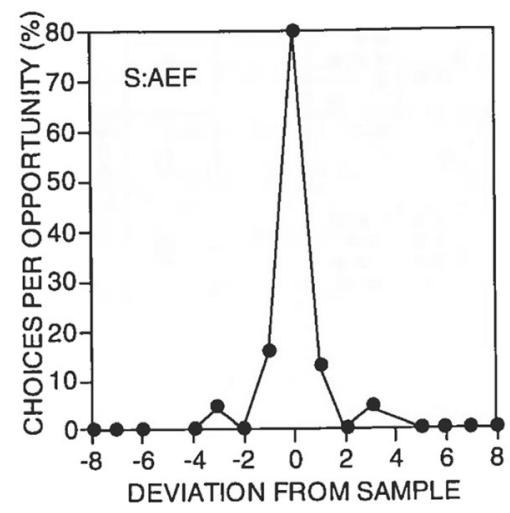

\begin{tabular}{|l|c|c|c|c|c|c|}
\hline Sample & 7 & 8 & 6 & 7 & 4 & 8 \\
\hline Error & 6-dots & 5-dots & 7-dots & 6-dots & 5-dots & 7-dots \\
\hline
\end{tabular}

\begin{tabular}{|l|c|c|c|c|c|}
\hline Sample & "three" & "seven" & "seven" & "four" & "eight" \\
\hline Error & 4-dots & 8-dots & 6-dots & 7-dots & 7-dots \\
\hline
\end{tabular}

Fig. 2 Top: Subject AEF's generalization gradient with numerals and dots, showing the relation of the subject's choices to the sample in the number sequence. Bottom: Actual errors 
more interesting possibility. In these tests, subjects matched numerals to number names; no actual quantities (dots) were involved. When the sample was a numeral, the choices were printed words, and vice versa, as illustrated in Fig. 3. Other tests offered the subjects the same choices but the samples were auditory (dictated) number names.

Again, patients had problems doing these tasks accurately. And again, their errors were not random. One subject, for example, when tested a week after her stroke, showed only slightly less than normal accuracy (88\% correct) in the simultaneous matching of numerals to printed digit names, but there was still a definite relation of proximity in the number sequence between each error and what would have been the correct choice (Fig. 4, left). The actual errors, in order of occurrence, are as shown in Table 1 (left column).

In other tests, this patient was quite unable to match dictated number names to printed numerals or number names (18\% correct), and the early generalization gradient showed no relation within the number sequence between errors and correct choices (Fig. 4, center). When the tests with auditory samples were repeated three weeks later, however, her accuracy was much greater $(67 \%$ correct) and her errors were now related to the correct choices by proximity in the number sequence (Fig. 4, right). The actual errors are shown in Table 1 (right column). These test results were interesting not simply because they provided a quantitative description of patients' stroke-induced difficulties but because they showed patients to be making the same kinds of errors when matching symbols to each other as when matching those symbols to their referents. The patients were reacting to numerals and number names as if those symbols were actual quantities.

We saw similar results when we tested some aphasic patients who had problems matching color names to colors. The most prevalent errors were confusions among red, orange, and yellow and between green and blue. Perhaps these errors were due to physical resemblances among the colors. But then, we saw the patients making the same kinds of errors when matching dictated color-name samples to printed color-name choices. Although the latter tests involved only the color names, the patients' errors were like those they made in tests that involved the actual colors. These patients were reacting to auditory and visual color names as if those language symbols were the colors themselves.

We summarized our findings as follows (from Leicester et al., 1971, with some modifications):

Relevant stimulus characteristics are those that relate the sample to the correct choice: by their use the task can be done correct]y....[A] distinction among

a

\begin{tabular}{|c|c|c|}
\hline 2 & 6 & 1 \\
\hline 4 & one & 3 \\
\hline 8 & 7 & 5 \\
\hline
\end{tabular}

b

\begin{tabular}{|c|c|c|}
\hline seven & four & six \\
\hline five & 1 & two \\
\hline three & eight & one \\
\hline
\end{tabular}

Fig. 3 Tests with numerals and number names. Illustrative trials, simultaneous matching. a Visual number name sample, numeral choices. b Visual numeral sample, number name choices 

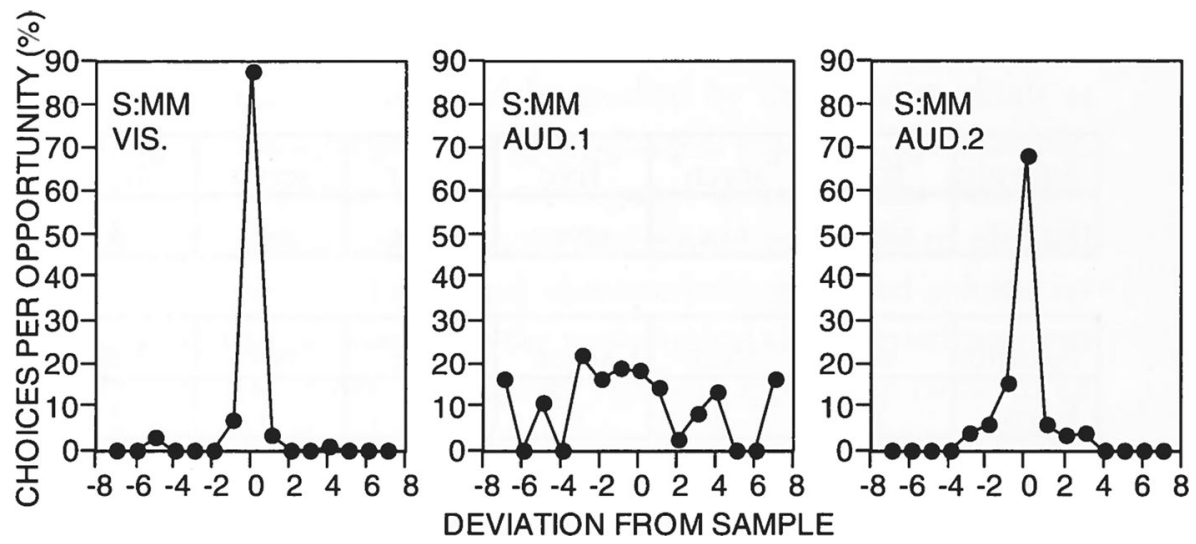

Fig. 4 Subject M.McL's generalization gradients showing the relation of a subject's choices to the sample within the number sequence. Left panel: visual samples and choices. Middle and right panels: auditory samples and visual choices

relevant characteristics is between physical characteristics and language characteristics. Physical characteristics describe the shape, [quantity], color, [brightness], size, etc. of visual stimuli; the loudness, pitch, etc. of auditory stimuli; the shape, etc. of tactile stimuli; ...Language characteristics describe nonphysical aspects of language symbols. They are arbitrary, learned by convention, and transfer between auditory and visual modalities. We were surprised to find that language characteristics could be studied by the same methods as physical characteristics, by generalization gradients, for example, and that responses related to language characteristics were governed by similar laws to those that govern responses to physical characteristics... [Language] characteristics governed aphasic errors in a manner similar to the way physical characteristics

Table 1 Errors made by one participant. See text for more information

\begin{tabular}{llll}
\hline $\begin{array}{l}\text { Matching visual numerals } \\
\text { to visual number names } \\
\text { Sample }\end{array}$ & Error & \multicolumn{2}{l}{$\begin{array}{l}\text { Matching dictated number names to visual } \\
\text { numerals and visual number words } \\
\text { Sample }\end{array}$} \\
\hline 4 & Three & "Five" & Error \\
5 & Four & "Seven" & Three \\
6 & Seven & "Five" & Six \\
9 & Four & "Four" & Seven \\
3 & Two & "Seven" & Five \\
2 & Six & "Five" & Six \\
3 & Two & "Six" & 3 \\
6 & Eight & "Four" & 3 \\
2 & Three & "Seven" & 3 \\
Five & 6 & "Five" & 6 \\
7 & Six & "Two" & 8 \\
& & "Three" & 3 \\
\hline
\end{tabular}


govern non-aphasic errors....Language symbols apparently come to be governed by the physical properties of the things they represent (pp. 152, 153).

We were almost there. Our patients had demonstrated strikingly that they were giving language symbols the properties of their referents, and we had the methods at hand to produce laboratory analogues of that phenomenon. If we had been more venturesome, we would have begun our work on equivalence relations at that point, but we were not yet ready. The notion that we might be able to describe equivalence relations in a way that could account for our observations about symbols and their referents was still too great a conceptual leap. We had to wait until other considerations led us up that research path.

\section{Equivalence and Creativity}

Even if I were to stop at this point in my list, I think I would have justified my interest in equivalence relations. But there is still more substance to my reasons for that interest. Some of the studies my colleagues and I conducted may be regarded as the beginnings of a functional analysis of elementary reading comprehension, auditory comprehension, and oral reading. Our basic experimental paradigm provides a method for defining "comprehension." When the relation between words (written or spoken) and things can be shown to be an equivalence relation, then we can say that the words are understood. We have, here, an empirically verifiable method for distinguishing between meaningful and meaningless behavior-environment relations. The comprehension of written and spoken language, of course, involves much more than we have dealt with in our experiments, but we have laid down the foundations for the analysis of more complex cases.

One outcome of our early work on reading comprehension and equivalence relations is a method for generating new cognitive performances without having to teach each one separately. The very definition of equivalence relations requires the emergence of new performances from a baseline of explicitly arranged contingencies. This highlights the incredible efficiency of the experimental paradigm as a method of teaching. Even by itself, this practical outcome of the research is exciting, although its utility has gone largely unappreciated by the education establishment. The potential contribution of the equivalence research to instructional technology is for me one of the most compelling reasons for continuing the research.

In addition to its significance for the methodology of teaching, the emergence of new behavior that has not been explicitly taught is also the defining feature of creativity. Because creativity always involves the production of something new, it is feared by those who find change threatening and respected by those who recognize change as a prerequisite for progress. But whether one wants to rein in or promote the creative process, knowledge about how it works is necessary. Largely because we do not even recognize an ongoing creative process until it yields a new product, the process itself remains little understood; by the time we become aware of it, it is over. Many therefore consider creativity an unapproachable mystery, beyond our power of understanding.

Clearly, creativity involves more than just equivalence relations. Just as clearly, insofar as equivalence relations can underlie the emergence of untaught behavior, equivalence relations can also underlie creative acts. The more we understand equivalence, the more we understand creativity. To the extent that we can say, "Teach a 
person that $\mathrm{A}$ is related to $\mathrm{B}$, and $\mathrm{B}$ to $\mathrm{C}$, and then, without further teaching, you will find the person relating $\mathrm{C}$ to $\mathrm{A}, \mathrm{A}$ to $\mathrm{C}, \mathrm{B}$ to $\mathrm{A}$, and $\mathrm{C}$ to $\mathrm{A}$," we are predicting acts of creativity from a set of specified circumstances. This is exactly what has happened over and over in the research on equivalence. In the very process of testing for equivalence relations, we see creativity being displayed even by people who have been classified as nonlearners. The more we find out about equivalence relations, the better we will understand and thereby become able to generate desirable creative performances.

\section{The Problem of Induction}

Creativity has long occupied the attention of philosophers and logicians, but they call it induction. The classical definition of inductive inference is "the derivation of general principles from particular facts or instances." Why is this creativity? Inductive generalization entails the bringing together of a group of particulars into a set. At some point in any particular instance of inductive reasoning - in our classification of particulars into a set that is differentiated from other sets - an act of faith must occur; except when the particulars resemble each other physically, we have no reason for classifying them together except the generalization itself. We then go on to test the utility of the generalization, often by deductive inference, which is defined classically as "the derivation of particular facts or instances from general principles." It remains ever possible that the original inductive leap may turn out to have been unjustified. That is why an inductive inference - a generalization that is induced from particulars that seem unrelated on any other grounds - can never be proven indisputably. Inductive inference is therefore a pure act of creativity in the sense that the reasoning from particulars to generalization involves no purely logical or physical necessity.

This illogical feature of what has been called logical induction led me many years ago to state, "Induction is a behavioral process, not a logical one" (Sidman, 1960/1988, p. 59). Now, I think we can take an additional step. The behavioral work on equivalence relations permits us to describe and to demonstrate and investigate under controlled conditions at least one of the processes underlying the behavior that is called inductive inference.

My colleagues and I suggested that when features of the environment become related through behavioral contingencies, their relation is an equivalence relation if it possesses the properties of reflexivity, symmetry, and transitivity. There are several ways to find out empirically whether a given relation possesses these properties. One of them goes like this: we start with stimulus A being related in a particular way to stimulus B, and B being related in the same way to $\mathrm{C}$; then, if that relation is an equivalence relation, $\mathrm{A}$ will also be found to be related in the same way to C, C to A and to B, B to A, A to itself, B to itself, and $\mathrm{C}$ to itself. In some of our empirical work, we used conditional-discrimination procedures to establish a relation that included stimulus pairs that we may call $\mathrm{AB}$ and $\mathrm{BC}$; then, we provided evidence that the relation our procedures had established was an equivalence relation by showing that it also included the stimulus pairs $\mathrm{AC}, \mathrm{CA}, \mathrm{CB}, \mathrm{BA}$, $\mathrm{AA}, \mathrm{BB}$, and $\mathrm{CC}$. Once explicit reinforcement contingencies had established the original $\mathrm{AB}$ and $\mathrm{BC}$ relations, all the other relations were emergent - not having been involved in any reinforcement contingency. Their emergence was predictable by deductive inference, but the deductions were made possible only by a previous act of induction, a 
generalization from particulars - the particulars being the $\mathrm{AB}$ and $\mathrm{BC}$ stimulus pairs, and the generalization being the inclusion of these pairs in an equivalence relation. The generalization therefore provided the only basis for expecting the untaught relations to emerge. Given the inductive generalization, the deductive inferences were built in; the new relations had to be there.

What does all this say about inductive inference as a behavioral process? We have here an example of an inductive inference - that the $\mathrm{AB}$ and $\mathrm{BC}$ pairs are included in an equivalence relation - an inference that is required by no logical or physical necessity and is supported only by the subsequent observation of new related pairs, the emergence of which we have deduced from the definition of equivalence. Emergence of the new pairs tells us that our subject has made the same inferences, both inductive and deductive, that we have made. Although we express our inferences in words, our subjects need not verbalize their inferences; all of the environmental relations we teach a subject explicitly and those which emerge without having been explicitly taught show themselves in the subject's nonverbal selection of stimuli from a number of alternatives. I believe, then, it is fair to say that our empirical behavioral studies of the equivalence relation are at the same time empirical behavioral studies of inductive inference.

The statement, "If $\mathrm{A}$ is related to $\mathrm{B}$, and $\mathrm{B}$ to $\mathrm{C}$, then $\mathrm{C}$ is related in the same way to A," is based on inductive inference. The problem for mathematical set theory is to answer the question, "What general conditions will justify this induction?" Although I have taken a behavior analytic definition of equivalence from mathematical set theory, behavior analysis has a different question to answer: "What specific acts will justify this induction?" The behavioral problem is not to define the noun, induction, but to account for the verb, to induce. To the extent that our studies of equivalence relations help to solve that problem, we confirm the supposition that induction is a behavioral process. In bringing the study of equivalence relations into the behavior laboratory, we are at the same time submitting the problem of logical induction to an experimental analysis.

\section{References}

Chiesa, M. (1994). Radical behaviorism: the philosophy and the science. Boston: Authors Cooperative.

Grossman, D. (1989). See under: love. (translated from the Hebrew by Betsy Rosenberg). New York: Farrar Straus Giroux.

Hineline, P. N. (1980). Re-turning the operant-respondent distinction. In T. Thompson \& M. D. Zeiler (Eds.), Analysis and integration of behavioral units (pp. 55-79). Hillsdale, NJ: Lawrence Erlbaum and Associates.

Leicester, J., Sidman, M., Stoddard, L. T., \& Mohr, J. P. (1971). The nature of aphasic responses. Neuropsychologia, 9, 141-155.

Lissauer, H. (1890). Ein fall von seelenblindheit nebst einem beitrage zur theorie derselben. Archives of Psychiatry, 21, 222-270.

Mehegan, D. (1994). War of words erupts over 'rape' interview. Boston Globe, January 6, pp. 45, 50.

Schoenfeld, W. N. (1994). Religion and human behavior. Boston: Authors Cooperative.

Sidman, M. (1960/1988). Tactics of scientific research. New York, Boston: Basic Books, Authors Cooperative (reprinted).

Sidman, M., Stoddard, L. T., Mohr, J. P., \& Leicester, J. (1971). Behavioral studies of aphasia: methods of investigation and analysis. Neuropsychologia, 9, 119-140.

Skinner, B. F. (1957). Verbal behavior. New York: Appleton-Century-Crofts. 